\title{
Biliary Schwannoma That Required Differentiation from Bile Duct Cancer
}

\author{
Kazuhiro Takami ${ }^{a}$ Kuniharu Yamamoto ${ }^{a}$ Hiroto Sakurai $^{a}$ Noriko Kondo ${ }^{a}$ \\ Chikashi Shibata $^{\text {b }}$ Yu Katayose ${ }^{a}$ \\ ${ }^{a}$ Division of Hepato-biliary-pancreatic surgery, Tohoku Medical and Pharmaceutical \\ University, Sendai, Japan; ${ }^{b}$ Division of Gastoroenterologic surgery, Tohoku Medical and \\ Pharmaceutical University, Sendai, Japan
}

\section{Keywords}

Schwannoma $\cdot$ Bile duct cancer $\cdot$ Biliary schwannoma

\begin{abstract}
Schwannomas are benign tumors originating from Schwann cells, which are the main component of the neural sheath. Biliary schwannomas are extremely rare. We report the case of a 78-year-old man who presented with no abdominal symptoms or jaundice. CT imaging showed a hyperdense mass extending along the extrahepatic bile duct, and the upstream bile ducts were dilated. We performed extrahepatic bile duct resection under a preoperative diagnosis of the extrahepatic bile duct cancer. A histopathological examination of the resected specimen revealed that the tumor consisted of spindle cells which exhibited a palisading arrangement. Immunohistochemical staining was positive for protein S-100 and vimentin. Based on these pathological findings, we diagnosed the patient with schwannoma of the extrahepatic bile duct. Our search of the relevant literature revealed 19 case studies of biliary schwannomas. In our case, the surgical findings showed that the tumor was noninvasive and mobile. During surgery, a fast frozen section analysis was performed, and no malignant findings were observed. These results enabled us to avoid extrahepatic bile duct resection with major hepatectomy. We experienced a case of biliary schwannoma that was difficult to distinguish from bile duct cancer.
\end{abstract}

\section{Introduction}

Schwannomas are neoplasms that arise from Schwann cells of peripheral nerves, and $>90 \%$ are benign $[1,2]$. Schwannomas occur from all parts of the body, but the most common sites are the upper extremities, trunk, head and neck, retroperitoneum, mediastinum, pelvis, 
and retroperitoneum [3]. Schwannoma in the digestive organ is rare, and most such tumors are reported in the stomach, followed by the colorectum and esophagus [4]. Biliary schwannomas are extremely rare [3]. Our search of the relevant literature revealed 19 case studies of biliary schwannomas [3-21]. We present the case of a patient with a biliary schwannoma that required differentiation from extrahepatic bile duct cancer.

\section{Case Report}

A 78-year-old man was referred to our hospital after a mass was incidentally found in the right hepatic duct by CT. He had undergone open cholecystectomy for gallstones 13 years previously, and prostate cancer surgery 15 years previously. There was no evidence of jaundice or abdominal symptoms. An abdominal examination revealed a soft abdomen with no evidence of hepatomegaly. Laboratory studies revealed the following findings: leukocyte count, $6,500 / \mu \mathrm{L}$; red blood cell count, $4.71 \times 106 / \mu \mathrm{L}$; hemoglobin, $14.8 \mathrm{~g} / \mathrm{dL}$; total bilirubin, $0.9 \mathrm{mg} / \mathrm{dL}$; direct bilirubin, $0.1 \mathrm{mg} / \mathrm{dL}$; aspartate aminotransferase, $14 \mathrm{U} / \mathrm{L}$; alanine aminotransferase $14 \mathrm{U} / \mathrm{L}$; alkaline phosphatase, $189 \mathrm{U} / \mathrm{L}$; total protein, $6.3 \mathrm{~g} / \mathrm{dL}$; and total albumin, $3.4 \mathrm{~g} / \mathrm{dL}$. The tumor markers including CEA, CA19-9, DUPAN-2, and SPAN-1 were within the normal ranges. Contrastenhanced CT showed a hyperdense mass extending along the extrahepatic bile duct of the posterior segment, and the upstream bile ducts were dilated (Fig. 1a, b). Endoscopic retrograde cholangiopancreatography and magnetic resonance cholangiopancreatography revealed that the bile duct of the posterior segment was independently inserted into the common hepatic duct (Fig. 2). Subsequent biliary biopsy and biliary brushing using the SpyGlass peroral cholangioscopy system for cytology revealed benign findings. We planned surgical treatment without biliary intervention for decompression, with a preoperative principal differential diagnosis of extrahepatic bile duct cancer. We performed extrahepatic bile duct resection. At laparotomy, there was no liver metastasis or peritoneal dissemination. A hard mass was palpable in the hepatoduodenal ligament, but the tumor was noninvasive and mobile. We decided to perform limited resection intraoperatively because a fast frozen section analysis was negative for malignancy (Fig. 3a, b). After extrahepatic bile duct resection, biliary reconstruction was performed by the Roux-en-Y hepaticojejunostomy. A histopathological examination of the resected specimen revealed that the tumor consisted of spindle cells with wavy nuclei and exhibited a palisading arrangement (Fig. 4a, b, 5). Lymph node metastasis was not detected. Immunohistochemical staining was positive for protein S-100 (Fig. 6) and vimentin (Fig. 7) and negative for SMA (Fig. 8), desmin (Fig. 9), CD34 (Fig. 10), p53, and CD117 (c-kit) (Fig. 11). Based on these pathological findings, we diagnosed the patient with schwannoma of the extrahepatic bile duct. The surgical margin was negative, indicating complete resection. The patient's postoperative course was uneventful, and he has been doing well without any complications.

\section{Discussion}

Schwannomas are tumors that derive from Schwann cells, the main component of the neural sheath, and $90 \%$ are benign [1]. The most common locations are the upper extremities, trunk, head and neck, retroperitoneum, mediastinum, pelvis, and peritoneum [3]. Schwannomas of the digestive organs are rare; in most such cases, tumors are reported in the stomach, followed by the colorectum and esophagus [4]. Biliary schwannomas are extremely rare; our search of the relevant literature revealed 19 case studies of biliary schwannomas (Table 1). The biliary system is tightly innervated by both the sympathetic and parasympathetic nervous systems, and this tumor is thought to have originated from these nerve tissues [4].

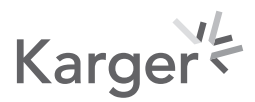



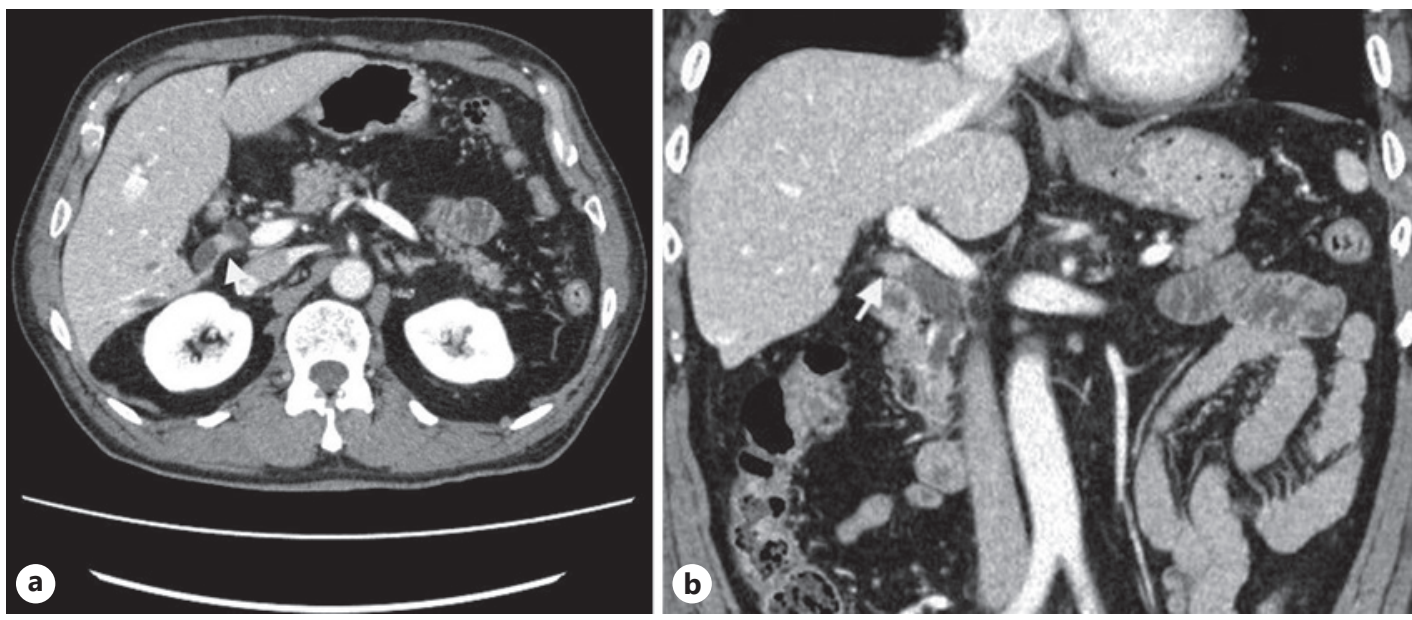

Fig. 1. a, b Contrast-enhanced CT showed a hyperdense mass extending along the extrahepatic bile duct of the posterior segment and dilatation of the upstream bile ducts. No swollen lymph nodes or metastatic lesions were observed.

Fig. 2. MRCP revealed that the bile duct of the posterior segment inserted independently into the common hepatic duct. These imaging findings showed local stenosis at the posterior segment of the bile duct. MRCP, magnetic resonance cholangiopancreatography.

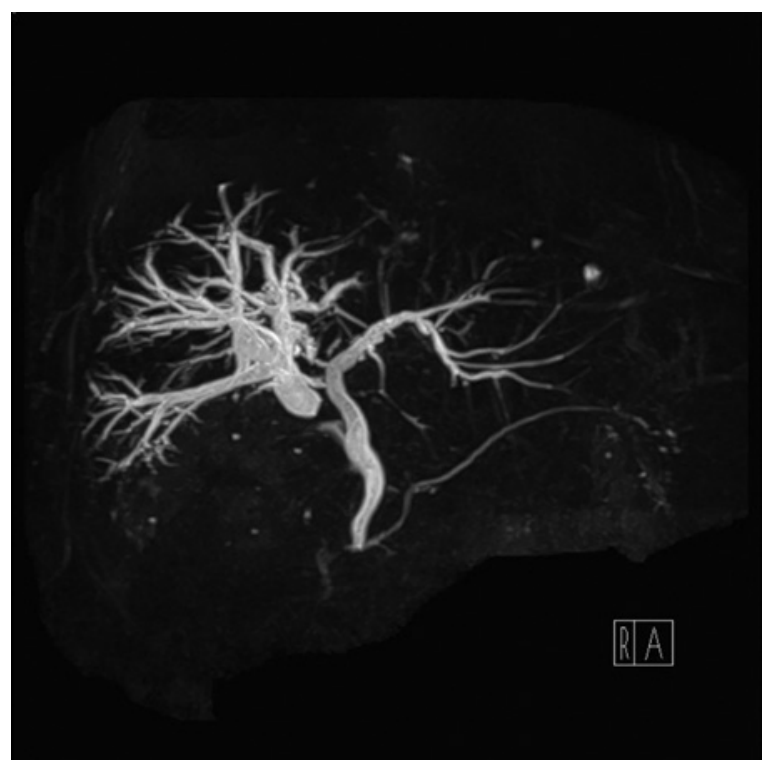

In previously reported cases, the age of the patients ranged from 15 to 78 years, with a sex ratio of 7:13. The most common symptom of bile duct schwannoma was jaundice, and other symptoms included abdominal pain and weight loss, but there were also asymptomatic cases $[3,4]$. Furthermore, there are no reliable tumor markers for biliary schwannomas. It is very difficult to make a preoperative diagnosis of biliary schwannoma based on imaging because there are no characteristic findings on ultrasonography or CT [21]. In these reports, preoperative biopsy was performed in 8 cases, but no preoperative diagnosis was possible. Only one of the 19 reported cases was preoperatively diagnosed with biliary schwannoma; the others were diagnosed with cholangiocarcinoma and other malignant tumors, GIST, benign tumors, cysts, and other conditions. Among these, there were 4 cases that were preoperatively diagnosed as cholangiocarcinoma. Thus, it was considered difficult to distinguish biliary schwannoma from malignant disease based on histopathological examinations and imaging findings before surgery (Table 1 ). 

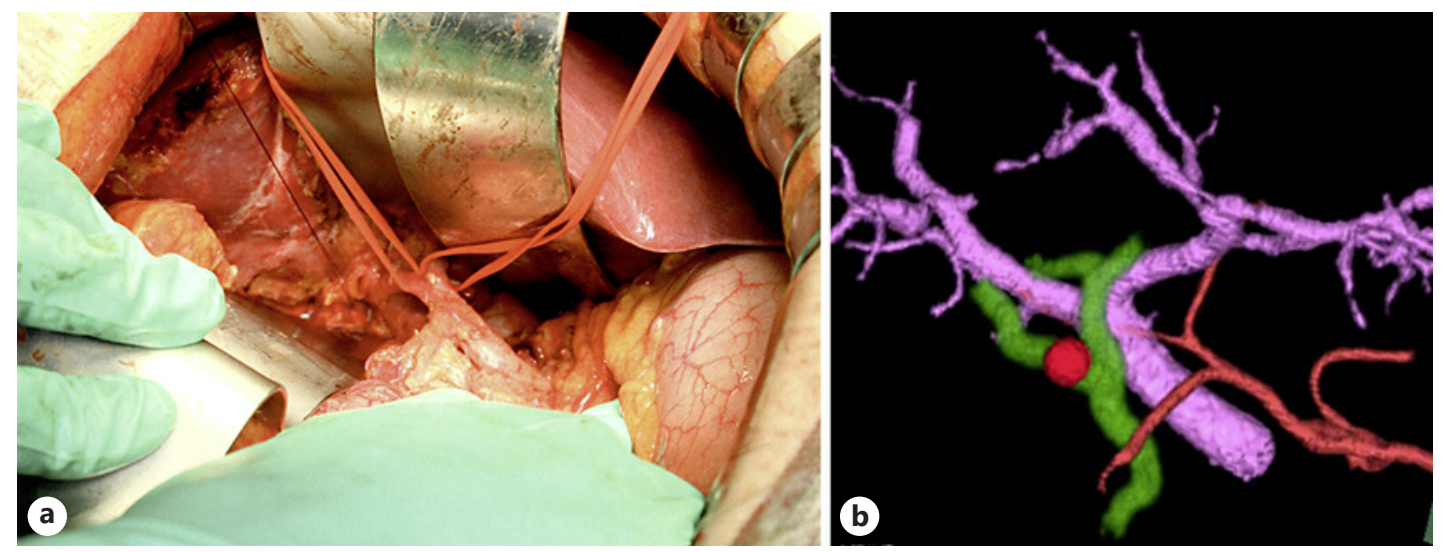

Fig. 3. a, b The decision to perform limited resection was made intraoperatively because a fast frozen section analysis was negative for malignancy. We performed extrahepatic bile duct resection and biliary reconstruction by Roux-en-Y hepaticojejunostomy.

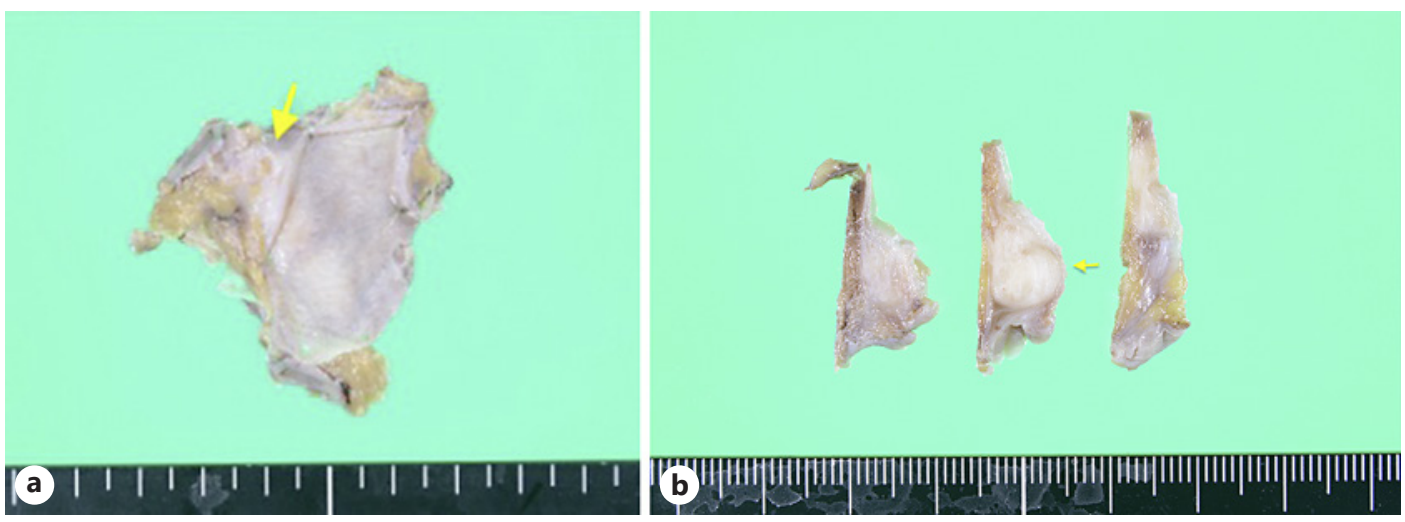

Fig. 4. a, b Gross findings of the resected specimen.

Fig. 5. A histopathological examination of the resected specimen revealed the tumor to consist of spindle cells with wavy nuclei and to exhibit palisading arrangement.

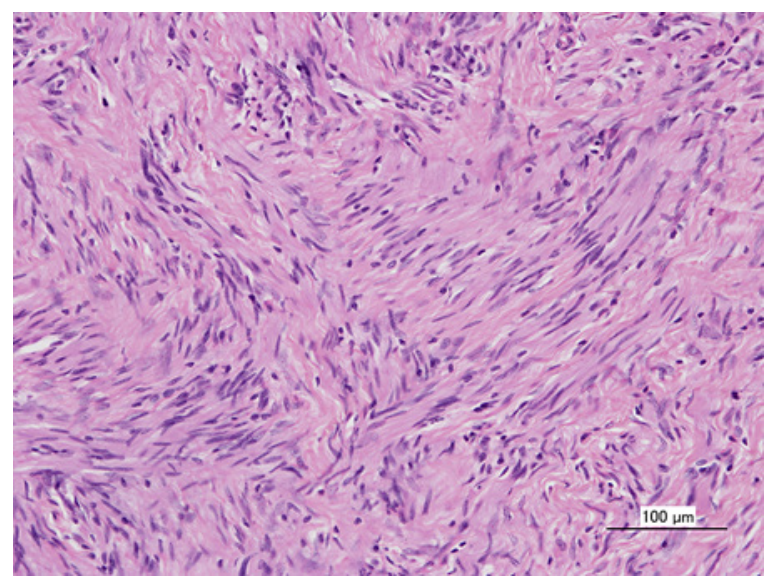

Histologically, a typical schwannoma consists of an Antoni A area and an Antoni B area. The Antoni A area is densely packed with spindle-shaped tumors with wavy nuclei. A palisade arrangement of nuclei may also be observed. The Antoni B area is hypocellular, and there are loose tumors in the abundant myxoid stroma [22]. In schwannoma, immunohistochemical 
Fig. 6. Immunohistochemical staining was positive for protein S-100.

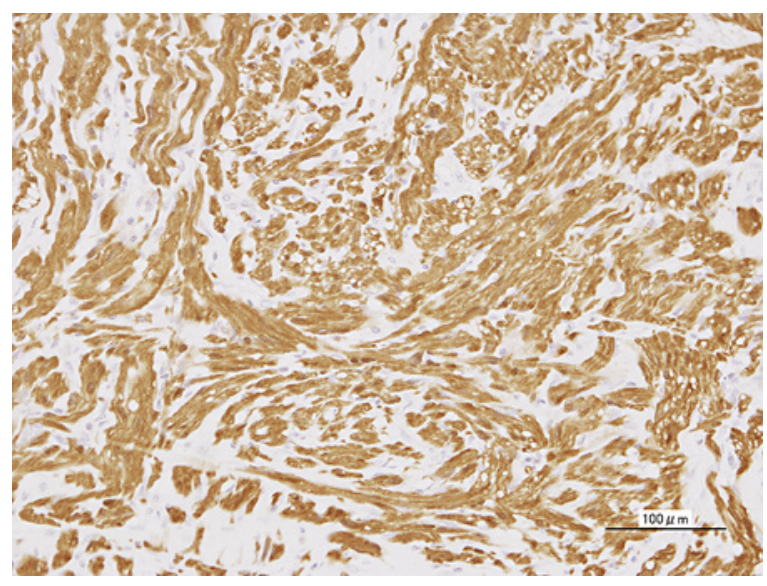

Fig. 7. Immunohistochemical staining was positive for vimentin.

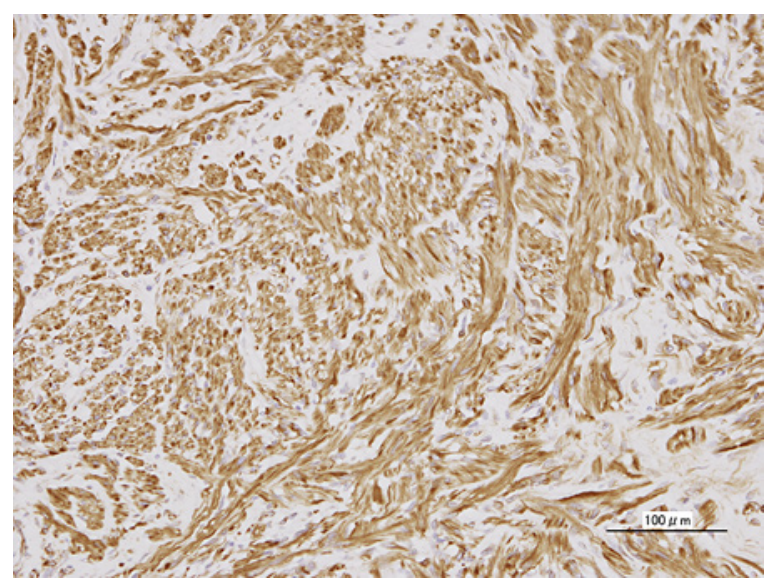

Fig. 8. Immunohistochemical staining was negative for SMA.

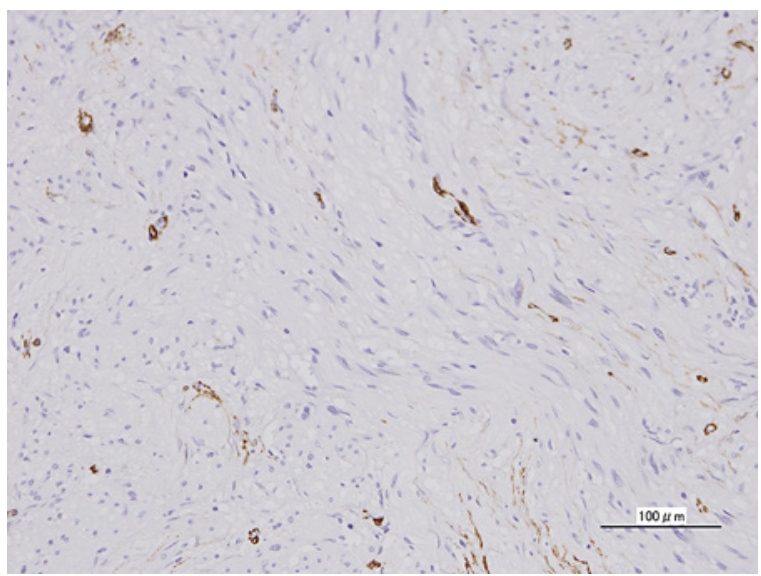

staining is strongly positive for neural markers such as vimentin and S-100 and negative for muscle markers such as desmin, c-kit, and CD34. In our case, the histopathological examination and immunostaining showed similar results.

In our case, a biliary biopsy using the SpyGlass peroral cholangioscopy system was performed preoperatively, but no malignant findings were observed. However, a hypertrophic tumor of the bile duct wall was recognized, and the preoperative diagnosis was bile duct cancer. The surgical findings showed that the tumor was noninvasive and mobile. 
Fig. 9. Immunohistochemical staining was negative for desmin.

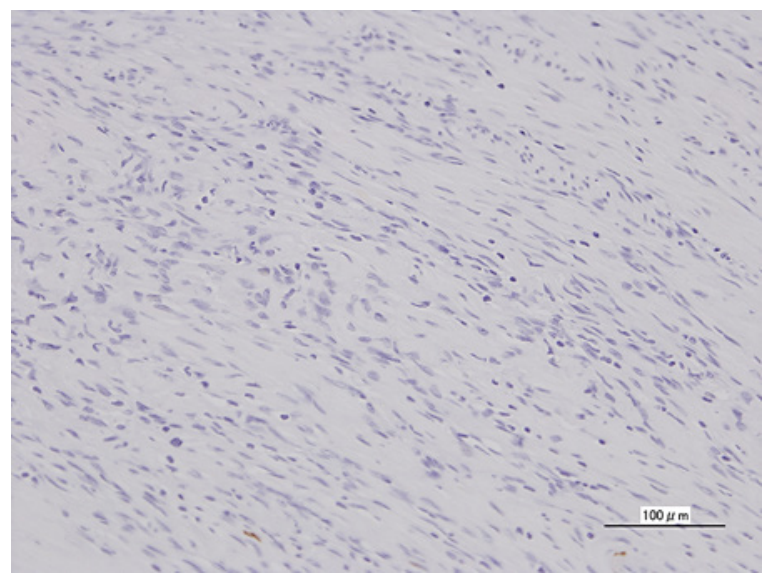

Fig. 10. Immunohistochemical staining was negative for CD34.

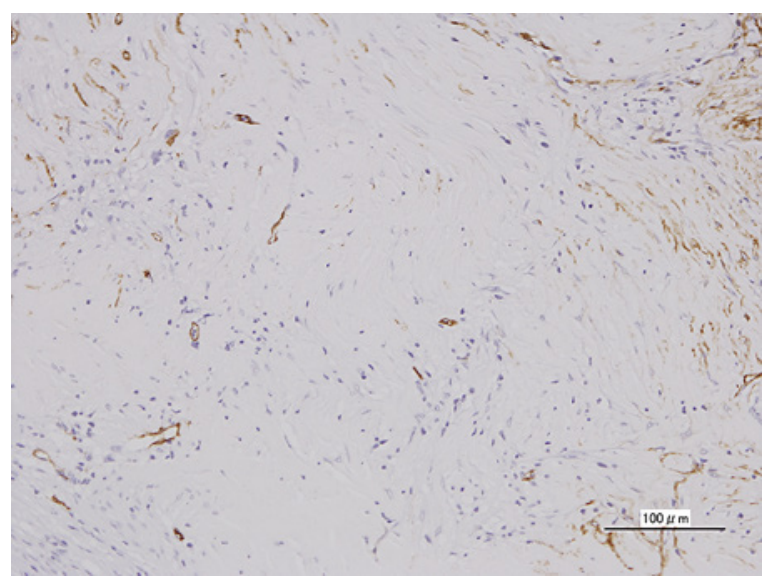

Fig. 11. Immunohistochemical staining was negative for c-kit.

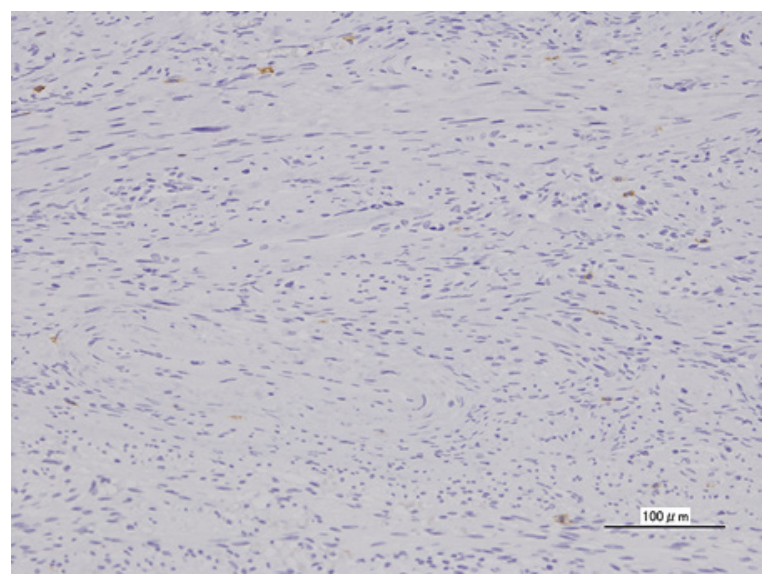

During surgery, a fast frozen section analysis was performed, and no malignant findings were observed. These results enabled us to avoid extrahepatic bile duct resection with major hepatectomy, which is a standard procedure for bile duct cancer of this site.

We experienced a case of biliary schwannoma that was difficult to distinguish from cholangiocarcinoma. Biliary schwannomas, like schwannomas at other locations, have a good prognosis in patients treated with complete resection. Thus, for this disease, there is a demand for surgery that is adequate in consideration of the tumor site and size. In recent years, 
Table 1. Nineteen case studies of biliary schwannoma reported in the literature

\begin{tabular}{|c|c|c|c|c|c|}
\hline Reference & Age/sex & Symptoms & Biopsy & Preoperative diagnosis & Tumor location \\
\hline Whisnant et al. [5] & $15 / F$ & $\begin{array}{l}\text { Abdominal pain, } \\
\text { jaundice, weight loss }\end{array}$ & No & & $\begin{array}{l}\text { Distal common } \\
\text { bile duct } \\
\end{array}$ \\
\hline Balart et al. [6] & $56 / F$ & $\begin{array}{l}\text { Abdominal pain, } \\
\text { jaundice }\end{array}$ & No & Choledocholithiasis & $\begin{array}{l}\text { Common } \\
\text { hepatic duct }\end{array}$ \\
\hline Oden et al. [7] & $40 / \mathrm{F}$ & $\begin{array}{l}\text { Abdominal pain, } \\
\text { jaundice }\end{array}$ & No & Choledocholithiasis & $\begin{array}{l}\text { Common bile } \\
\text { duct }\end{array}$ \\
\hline Jakobs et al. [8] & $37 / \mathrm{M}$ & $\begin{array}{l}\text { Abdominal pain, } \\
\text { jaundice }\end{array}$ & Yes & $\begin{array}{l}\text { Intraductal benign } \\
\text { tumor }\end{array}$ & $\begin{array}{l}\text { Common } \\
\text { hepatic duct }\end{array}$ \\
\hline Honjo et al. [9] & $48 / F$ & Jaundice & Yes & $\begin{array}{l}\text { Benign nonepithelial } \\
\text { tumor }\end{array}$ & $\begin{array}{l}\text { Common bile } \\
\text { duct }\end{array}$ \\
\hline Otani et al. [10] & $59 / F$ & Abdominal pain & No & $\begin{array}{l}\text { Remnant choledochal } \\
\text { cyst }\end{array}$ & $\begin{array}{l}\text { Intrapancreatic } \\
\text { bile duct } \\
\end{array}$ \\
\hline Park et al. [11] & $53 / \mathrm{F}$ & Asymptomatic & No & & Porta hepatis \\
\hline Vyas et al. [12] & $29 / F$ & $\begin{array}{l}\text { Abdominal pain, } \\
\text { jaundice }\end{array}$ & Yes & & $\begin{array}{l}\text { Common bile } \\
\text { duct }\end{array}$ \\
\hline Kamani et al. [13] & $39 / F$ & Jaundice, weight loss & No & Klatskin tumor & $\begin{array}{l}\text { Proximal } \\
\text { common } \\
\text { hepatic duct }\end{array}$ \\
\hline Fenoglio et al. [14] & $41 / \mathrm{F}$ & Jaundice, weight loss & No & Pancreatic tumor & $\begin{array}{l}\text { Middle } \\
\text { common bile } \\
\text { duct }\end{array}$ \\
\hline Jung et al. [15] & $64 / F$ & Asymptomatic & Yes & & $\begin{array}{l}\text { Proximal } \\
\text { common bile } \\
\text { duct }\end{array}$ \\
\hline $\begin{array}{l}\text { Madhusudhan } \\
\text { et al. [16] }\end{array}$ & $46 / \mathrm{M}$ & Jaundice & No & Cholangiocarcinoma & $\begin{array}{l}\text { Intrahepatic } \\
\text { bile duct }\end{array}$ \\
\hline Kulkarni et al. [17] & $38 / \mathrm{M}$ & $\begin{array}{l}\text { Abdominal pain, } \\
\text { jaundice, weight loss }\end{array}$ & No & GIST, lymph nodal mass & Porta hepatis \\
\hline De Sena et al. [18] & $58 / F$ & Jaundice & No & Biliary schwannoma & $\begin{array}{l}\text { Extrahepatic } \\
\text { bile duct }\end{array}$ \\
\hline $\begin{array}{l}\text { Parameshwarappa } \\
\text { et al. [19] }\end{array}$ & $38 / \mathrm{M}$ & $\begin{array}{l}\text { Abdominal pain, } \\
\text { jaundice, weight loss }\end{array}$ & No & GIST, lymph nodal mass & $\begin{array}{l}\text { Common bile } \\
\text { duct }\end{array}$ \\
\hline Panait et al. [20] & $54 / F$ & $\begin{array}{l}\text { Gastroesophageal } \\
\text { reflex symptom }\end{array}$ & Yes & Metastatic melanoma & Porta hepatis \\
\hline Fonseca et al. [4] & $24 / \mathrm{M}$ & $\begin{array}{l}\text { Abdominal pain, } \\
\text { jaundice, weight loss }\end{array}$ & No & Klatskin tumor & $\begin{array}{l}\text { Proximal } \\
\text { common } \\
\text { hepatic duct }\end{array}$ \\
\hline Campos et al. [3] & $62 / M$ & $\begin{array}{l}\text { Abdominal pain, } \\
\text { jaundice }\end{array}$ & Yes & Cholangiocarcinoma & $\begin{array}{l}\text { Common } \\
\text { hepatic duct }\end{array}$ \\
\hline Xu et al. [21] & $31 / \mathrm{F}$ & $\begin{array}{l}\text { Abdominal pain and } \\
\text { distension }\end{array}$ & Yes & Benign tumor & $\begin{array}{l}\text { Intrahepatic } \\
\text { bile duct, porta } \\
\text { hepatis, } \\
\text { gallbladder }\end{array}$ \\
\hline Our case & $78 / \mathrm{M}$ & Asymptomatic & Yes & Cholangiocarcinoma & Porta hepatis \\
\hline
\end{tabular}


diagnostic ability has dramatically increased with improvements in image quality, cholangioscope operability, and the development of new treatment tools. These advances are expected to facilitate the accurate preoperative diagnosis of biliary schwannomas in the future.

\section{Statement of Ethics}

Written informed consent was obtained from the patient for publication of this case report and accompanying images. This study has been approved by the Research Ethics Committee of Tohoku Medical and Pharmaceutical University. Approved No. 2020-4-019.

\section{Conflict of Interest Statement}

The authors have no conflicts of interest to declare.

\section{Funding Sources}

There was no funding related to this research.

\section{Author Contributions}

Kazuhiro Takami and Yu Katayose were involved in study design and data interpretation. All authors were involved in the data analysis. All authors critically revised the report, commented on drafts of the manuscript, and approved the final report.

\section{References}

1 Hajdu SI. Peripheral nerve sheath tumors. Histogenesis, classification, and prognosis. Cancer. 1993;72:3549-52.

2 Das Gupta TK, Brasfield RD. Tumors of peripheral nerve origin: benign and malignant solitary schwannoma CA Cancer J Clin. 1970;20:228-33.

3 Campos CM, Sanz IG, Nova JL, Anca AV, Perez ME. Schwannoma of the biliary tract resembling cholangiocarcinoma: a case report and review. Ann R Coll Surg Engl. 2016;98:143-6.

4 Fonseca GM, Montagnini AL, Rocha MS, Patzina RA, Bernardes MV, Cecconello I, et al. Biliary tract schwannoma: a rare cause of obstructive jaundice in a young patient. World J Gastroenterol. 2012;18(37):5305-8.

5 Whisnant JD, Bennett SE, Huffman SR, Weiss DL, Parker JC, Griffen WO. Common bile duct obstruction by granular cell tumor (schwannoma). Am J Dig Dis. 1974;19(5):471-6.

6 Balart LA, Hines C, Mitchell W. Granular cell schwannoma of the extrahepatic biliary system. Am J Gastroenterol. 1983;78(5):297-300.

7 Oden B. Neurinoma of the common bile duct; report of a case. Acta Chir Scand. 1955;108(5):393-7.

8 Jakobs R, Albert J, Schilling D, Nuesse T, Riemann JF. Schwannoma of the common bile duct: a rare cause of obstructive jaundice. Endoscopy. 2003;35(5):695-7.

9 Honjo Y, Kobayashi Y, Nakamura T, Takehira Y, Kitagawa M, Ikematsu Y, et al. Extrahepatic biliary schwannoma. Dig Dis Sci. 2003;48(11):2221-6.

10 Otani T, Shioiri T, Mishima H, Ishihara A, Maeshiro T, Matsuo A, et al. Bile duct schwannoma developed in the remnant choledochal cyst-a case associated with total agenesis of the dorsal pancreas. Dig Liver Dis. 2005; 37(9):705-8.

11 Park MK, Lee KT, Choi YS, Shin DH, Lee JY, Lee JK, et al. (A case of benign schwannoma in the porta hepatis). Korean J Gastroenterol. 2006;47:164-7.

12 Vyas FL, Jesudason MR, Samuel R, Govil S, Jesudason SR. Schwannoma of bile duct--a case report. Trop Gastroenterol. 2006;27(1):50-1.

13 Kamani F, Dorudinia A, Goravanchi F, Rahimi F. Extrahepatic bile duct neurilemmoma mimicking Klatskin tumor. Arch Iran Med. 2007;10(2):264-7. 
14 Fenoglio L, Severini S, Cena P, Migliore E, Bracco C, Pomero F, et al. Common bile duct schwannoma: a case report and review of literature. World J Gastroenterol. 2007;13(8):1275-8.

15 Jung JH, Joo KR, Chae MJ, Jang JY, Lee SG, Dong SH, et al. Extrahepatic biliary schwannomas: a case report. J Korean Med Sci. 2007;22:549-52.

16 Madhusudhan KS, Srivastava DN, Dash NR, Gupta C, Gupta SD. Schwannoma of both intrahepatic and extrahepatic bile ducts: a rare case. Br J Radiol. 2009:e212-5.

17 Kulkarni N, Andrews SJ, Rao V, Rajagopal KV. Case report: benign porta hepatic schwannoma. Indian J Radiol Imaging. 2009;19(3):213-5.

18 De Sena G, Molino C, De Riitis MR, Candela S, Cifarelli V, Di Maio V, et al. (Surgical management of schwannoma of biliary tract). Chir Ital. 2009;61(1):119-21.

19 Parameshwarappa S, Rodrigues G, Kumar S, Patil B, Valliathan M. Schwannoma of common bile duct causing obstructive jaundice. Indian J Surg. 2010;72(1):333-5.

20 Panait L, Learn P, Dimaio C, Klimstra D, Do KG, Schwarz T, et al. Resection of perihilar biliary schwannoma. Surg Oncol. 2011;20(4):e157-9.

21 Xu S, Guo H, Shen Y, Sun K, Xie H, Zhou L, et al. Multiple schwannomas synchronously occurring in the porta hepatis, liver, and gallbladder: first case report. Medicine. 2016;95:e4378.

22 Lee WH, Kim TH, You SS, Choi SP, Min HJ, Kim HJ, et al. Benign schwannoma of the liver: a case report. J Korean Med Sci. 2008;23:727-30. 